\title{
Experimental rainfall-runoff data: Reconsidering the concept of infiltration capacity
}

\author{
Christoph Langhans ${ }^{\mathrm{a}, *}$, Gerard Govers ${ }^{\mathrm{a}}$, Jan Diels ${ }^{\mathrm{a}}$, Annemie Leys ${ }^{\mathrm{b}}$, Wim Clymans ${ }^{\mathrm{a}}$, An Van den Putte ${ }^{\mathrm{a}}$, \\ Jan Valckx ${ }^{\mathrm{a}}$ \\ ${ }^{a}$ Department of Earth and Environmental Sciences, K.U. Leuven, Celestijnenlaan 200 E, 3001 Heverlee, Belgium \\ ${ }^{\mathrm{b}}$ Policy Division, Department of Agriculture and Fisheries, Flemish Government, Ellipsgebouw, 7th floor, Koning Albert II-Laan 35, Bus 40, 1030 Brussels, Belgium
}

\section{A R T I C L E I N F O}

\section{Article history:}

Received 20 July 2009

Received in revised form 5 February 2010

Accepted 8 January 2011

Available online 19 January 2011

This manuscript was handled by K. Georgakakos, Editor-in-Chief, with the assistance of Christa D. Peters-Lidard, Associate Editor

\section{Keywords:}

Infiltration

Rainfall intensity

Microtopography

Sealing

Effective hydraulic conductivity

\begin{abstract}
S U M M A R Y
Many infiltration models rely on an effective hydraulic conductivity parameter $\left(K_{\mathrm{e}}\right)$ which is often determined in the field from rainfall simulation experiments on small plots. $K_{\mathrm{e}}$ can be defined as the spatially averaged infiltration capacity when the soil is 'field-saturated' and steady state is reached. Then it equals the infiltration rate $(f)$, provided ponding occurs. When a homogeneous surface is assumed, with negligible ponding depth, $K_{\mathrm{e}}$ is constant and does not vary with rainfall intensity $(r)$.

We developed a drop infiltrometer that allows measuring $K_{\mathrm{e}}$ on small plots under simulated rainfall intensities that vary between experiments. Infiltration experiments were conducted on a winter wheat field in the Belgian Loess Belt and various surface and soil properties were measured. Furthermore, photos were taken of the soil surface during the infiltration experiments for the determination of the inundated surface fraction.

The results of the experiments show that $K_{\mathrm{e}}$ is strongly dependent on rainfall intensity. In a statistical approach a dynamic $K_{\mathrm{e}}$ could be estimated with a function of rainfall intensity, tillage treatment, percentage residue cover and bulk density. Observations indicate that microtopography, surface fraction covered by a sedimentary seal and macroporosity interact with rainfall intensity, surface ponding and infiltration.

We propose that $K_{\mathrm{e}}$ in physically based infiltration models should either be made dependent on dynamic state variables in a mechanistic way, such as ponding depth and water content or made dependent on rainfall intensity using an empirical relationship. With such adaptations, both surface runoff and erosion models might have more potential to deal with scale effects in runoff generation.
\end{abstract}

(ㄷ) 2011 Elsevier B.V. All rights reserved.

\section{Introduction}

During a rainfall event, soil moisture and suction head profiles change as the wetting front moves downwards. Once the wetting front has moved far enough, the effect of suction on infiltration capacity becomes very small and it approaches the value of the effective hydraulic conductivity $\left(K_{\mathrm{e}}\right)$. A heterogeneous soil above the wetting front will be partly saturated and partly less saturated, with air filled porosity. At this 'field-saturation' and when steady state is reached, $K_{\mathrm{e}}$ is the spatial average of hydraulic conductivities and it is equal to the infiltration rate $(f)$. A minimal condition for field-saturation is that at least some ponding occurs somewhere within a unit of soil surface or plot.

When a homogeneous soil is assumed, which is ponded completely with a negligible ponding depth, any variation in rainfall

\footnotetext{
* Corresponding author. Tel.: +32 16326437; fax: +32 16322980 .

E-mail addresses: christoph.langhans@ees.kuleuven.be (C. Langhans), gerard. govers@ees.kuleuven.be (G. Govers), jan.diels@ees.kuleuven.be (J. Diels), annemie. leys@lv.vlaanderen.be (A. Leys), wim.clymans@ees.kuleuven.be (W. Clymans), an.vandenputte@ees.kuleuven.be (An Van den Putte), jan.valckx@ees.kuleuven.be (J. Valckx).
}

intensity ( $r$ ), given $r>f$, will have no effect on $K_{\mathrm{e}}$. But Hawkins and Cundy (1987) have shown that within a given area, say a plot or a hillslope, there exists a distribution of infiltration capacity or hydraulic conductivity, rather than a single value. This implies that at a given rainfall intensity some patches might pond and produce rainfall excess, while others do not. Their 'apparent' infiltration rate at steady state $\left(f_{\mathrm{s}}\right)$ is defined as area-averaged infiltration rate of which a certain fraction contributes to rainfall excess production. Infiltration capacities can be assumed to have an exponential distribution (Hawkins and Cundy, 1987), so $f_{\mathrm{s}}$ can be given by:

$F_{\mathrm{s}}=f_{\max }\left(1-\exp \left(-r / f_{\max }\right)\right)$

with $f_{\max }$ being the average infiltration rate, when the whole plot is contributing to rainfall excess production. With given $f$ and $r$, the model has only one empirical parameter, $f_{\max }$, which makes it attractive for practical use. Yu et al. (1997) and Stone et al. (2008) applied the exponential model to their rainfall-runoff data, which yielded much better results than the application of a model with a constant $K_{\mathrm{e}}$.

The definition of $f_{\mathrm{s}}$ in Eq. (1) implies that at any rainfall intensity there are patches that contribute to runoff and that the soil is at 
least partly saturated. This means that the definition of $f_{\mathrm{s}}$ is exactly the same as the definition given above for $K_{\mathrm{e}}$ and it can be concluded that $K_{\mathrm{e}}$ is dependent on rainfall intensity. Indeed, experimental studies that measure steady state infiltration rates at different rainfall intensities usually find increasing infiltration with rainfall intensity (Karssenberg, 2006; Stone et al., 2008). Plot studies under natural rainfall confirm this trend (Leonard et al., 2006; Yu et al., 1997). The concept of randomly distributed infiltration capacities is only one way to explain the observed $f-r$ relationship. Dunne et al. (1991) observed a strong relationship between rainfall intensity and infiltration rate on rangeland plots. They explained this with the inundation of mounds around grassed patches, which have a higher infiltration capacity. In a laboratory experiment Fox et al. (1998) proved that the increase in ponding depth within an inundated micro-depression increases infiltration more than can be explained solely by the increased hydraulic gradient. They attributed this to characteristic sealing conditions in the microtopography of an agricultural soil. Gradual inundation of a larger fraction of structural seal with increased rainfall intensity causes significantly higher infiltration rates. Boiffin (1984) and Bresson and Boiffin (1990) described the process of sealing on agricultural, loamy soils, that are also common to our study area. After tillage, raindrop impact creates a thin structural seal by disaggregation and the gradual decrease in pore volume through plastic deformation. When during rainfall the shear strength of the soil surface drops below a critical value, a sedimentary seal develops in the micro-depressions. Relocation of small aggregates and particles from the micro-slopes and sedimentation from runoff contribute to the formation of this sedimentary seal. Infiltration capacity of the structural seal is higher than that of the sedimentary seal by at least one order of magnitude. Inundation does not only depend on rainfall intensity, but also on the height of the microtopography and the connectivity between depressions when they become ponded (Darboux et al., 2002). Activation of preferential flow through macropores, when becoming inundated, is also considered to contribute to increasing infiltration rates with rainfall intensity (Weiler, 2005).

In hydrological and erosion modelling a correct determination of $K_{\mathrm{e}}$ is essential for the calculation of infiltration excess runoff generation. Calibration exercises of runoff-erosion models, such as of LISEM or EUROSEM, have shown that the effective or saturated hydraulic conductivity ( $K_{\mathrm{e}}$ or $K_{\mathrm{sat}}$ ) is one of the model parameters to which model results, both in terms of runoff and erosion, are most sensitive (Jetten et al., 1998; Veihe and Quinton, 2000).

Therefore, it is important to revise the view of an invariant $K_{\mathrm{e}}$. A mechanistic approach would be to explicitly model preferential flow, ponding depth and inundation at the surface and their interactions with other sources of heterogeneity. For this, accurate information on processes and distributions would be required. Rainfall intensity in such a conception is a driver or input, with only an indirect causal connection to hydraulic conductivity. The practical approach that this paper presents is to predict $K_{\mathrm{e}}$ in a statistical manner similar to pedo-transfer functions (PTFs), relating $K_{\mathrm{e}}$ to any possibly relevant and easy to measure variable, including rainfall intensity, which makes $K_{\mathrm{e}}$ 'dynamic'. Rainfall intensity in this concept is a statistical proxy that 'stands' and accounts for the effects of a heterogeneous soil on infiltration rates.

When variable rainstorms are simulated within infiltration models that require an effective hydraulic conductivity, a dynamic $K_{\mathrm{e}}$ can function equally well as a constant $K_{\mathrm{e}}$. There might be a small lag time of the effect of rainfall intensity on hydraulic conductivity, but when time steps are chosen appropriately, there is no theoretical problem in applying the concept. This is also true for the Time Compression Approximation (TCA) (Reeves and Miller, 1975). A dynamic $K_{\mathrm{e}}$ would change the form of the cumulative infiltration curve, but the assumption of TCA that temporal variability in the supply of infiltration water is quickly redistributed within the wetted soil profile remains untouched. It would be an interesting study to compare a constant with a dynamic $K_{\mathrm{e}}$ within any TCA model.

Finally, models need to be tested before any conclusion on the applicability of the dynamic $K_{\mathrm{e}}$ approach can be drawn, which is beyond the scope of this paper. But the results of Stone et al. (2008), who applied a rainfall intensity-dependent final infiltration rate to model plot runoff, are promising.

The problem of rainfall intensity-dependency of $K_{\mathrm{e}}$ appears to have many dimensions. Understanding of the controls on spatial variability and interactions between infiltration capacities is still lacking. Moreover, especially on sealing soils, the study is complicated by the alteration of the soil surface by raindrop impact, when different rainfall intensities are applied to the same plot. This paper therefore (1) presents a methodology for measuring infiltration at different rainfall intensities that reduces bias by minimizing raindrop impact. Further objectives are (2) to study the relationship between rainfall intensity and infiltration rate with a limited dataset, considering tillage and various soil and surface properties and (3) to discover the role of inundation of the microtopography in the infiltration process under field conditions.

\section{Materials and methods}

\subsection{Experimental field}

Experiments with variable rainfall intensity on small runoff plots ( 0.8 by $0.8 \mathrm{~m}$ ) were conducted on one field that was split into a reduced, non-inversion tillage (RT) and a conventional, mouldboard tillage (CT) strip. The experimental field is located in the Belgian part of the Western and Central European Loess Belt, near Huldenberg $\left(50^{\circ} 46^{\prime} 35^{\prime \prime} \mathrm{N} ; 4^{\circ} 36^{\prime} 39^{\prime \prime} \mathrm{E}\right)$. The area is under intensive agricultural use and predominant crops are wheat, maize, sugar beet and potato. The splitting of the experimental field occurred in 2004, with maize as crop. Subsequent crops until 2008 where: wheat, sugar beet, wheat and wheat again. Annual average rainfall is around $800 \mathrm{~mm}$. High intensity rainstorms that occur from late spring to early summer meet a relatively low ground cover and can cause severe erosion, local flooding and sedimentation problems (Verstraeten et al., 2003). In April 2008, experiments were undertaken at 18 locations within the field, 9 on each tillage treatment, both planted with winter wheat with an average plant cover of $39 \%$ and a plant height of $5-10 \mathrm{~cm}$. The slope was straight to slightly concave, with a mean (and standard deviation) of $7.3 \%(1.5)$. The soil is a silt loam (FAO/USDA) with sand 33\% (3.8), silt 60\% (3.7) and clay 7\% (1.2).

\subsection{Drop infiltrometer experiments}

A drop infiltrometer was newly developed to meet the demand of producing a range of rainfall intensities for small plots with a sufficiently good drop distribution and a low kinetic energy per $\mathrm{mm}$ rainfall. This was to minimize differences in sealing stages between the applications of different rainfall intensities. A sketch showing the most important features of the experimental setup is given in Fig. 1 .

The infiltrometer had the appearance of a table and could be easily transported to the field. A total of 309 silicon tube capillaries with an inner diameter of $0.5 \mathrm{~mm}$ and a length of $12 \mathrm{~cm}$ hung below the perforated aluminium plate of the table and produced drops with a diameter of ca. $3.3 \mathrm{~mm}$. The distance between capillaries was $0.035 \mathrm{~m}$, covering a surface of $0.56 \mathrm{~m}^{2}$. A frame with legs that were adjustable in height between $0.7 \mathrm{~m}$ and $1.1 \mathrm{~m}$ supported the plate, which could be levelled in order to create the same water 
Legend:

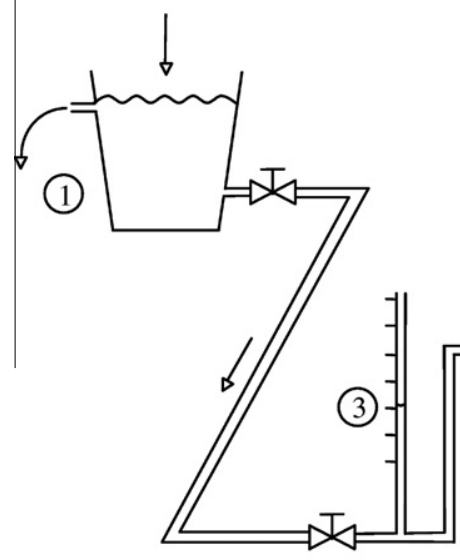

1. Constant head barrel with demineralised water, placed upslope

2. Valve to control inflow rate

3. Vertical transparent tube to monitor pressure

4. Dendritic tube system supplying the capillaries

5. Photo camera

6. Capillaries, hanging from an aluminium plate

7. Plot

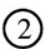

Fig. 1. Sketch of the experimental setup. Only the most important parts are sketched, a description is given in the legend within the figure.

pressure in each capillary. At the centre of the plate a camera was mounted above a hole, which was spared for the lens that protruded through the plate. Demineralised water from a constant head barrel installed upslope was conducted through a hose to the drop infiltrometer and distributed to the capillaries in a dendritic system of a plastic tube (30 $\mathrm{mm}$ inner diameter) and silicon tubes ( $3 \mathrm{~mm}$ inner diameter).The pressure head that controlled the flow rate of the capillaries was read from a vertical transparent tube, connected to the system, and could be controlled with a valve. The difference in pressure drop that occurs in the silicone tubes having different lengths between the plastic tube and the capillaries was calculated to be maximally $5 \%$. The kinetic energy of the drops after falling $0.8 \mathrm{~m}$ was $6.5 \mathrm{~J} \mathrm{~m}^{-2} \mathrm{~mm}^{-1}$, which is $20 \%$ of the kinetic energy the drops would have at terminal velocity. Christiansen's Coefficient of Uniformity (CU $=1-$ (deviation from mean/mean)) was measured in the lab for four different rainfall intensities: $96,48,24$ and $12 \mathrm{~mm} \mathrm{~h}^{-1}$ with CU of $0.87,0.91,0.88$ and 0.86 , respectively. The average uniformity coefficient over all intensities was 0.88 . The actual rainfall intensity was determined by catching the total rain just below the capillaries with a removable corrugated plate.

Prior to each experiment, $45 \mathrm{~mm} \mathrm{~h}^{-1}$ of rainfall from $3.25 \mathrm{~m}$ height from a nozzle-type simulator was applied to the plot until steady state runoff occurred, which was after 30-60 min. The results of this dry run are not reported here and details on design and usage of the nozzle simulator are reported in Leys et al. (2007). The rainfall with relatively high kinetic energy left the plot surface strongly sealed and wet at field capacity. This had the advantage that the following experiments with its relatively low kinetic energy brought about very little change in the sealing stage.

Each experiment consisted of four stages of rainfall intensity, ranging around $96,48,24$ and $12 \mathrm{~mm} \mathrm{~h}^{-1}$ and carried out in this order. The choice of halving the rainfall intensities rather than using a fixed interval was done in anticipation of the non-linear effects of the rainfall-runoff system. On windless days, the infiltrom- eter needed to be rocked gently by manual impulses on the aluminium plate with an interval of about $1 \mathrm{~s}$, in order to ensure a spatially random impact of drops. This was rarely necessary in the field, as slight wind sufficed to randomize drop impact. Runoff was caught in a gutter at the downslope end of the plot. A short pipe conducted the runoff to a hole, dug in the soil. Here, runoff was collected at time steps of $30 \mathrm{~s}$ and its volume was read from a transparent beaker. At the lowest intensity this time step was increased to $60-240 \mathrm{~s}$, in order to have a more accurate reading of the volumes.

Usually, the experiments started between 10 and 30 min after the first wetting of the plot with the nozzle rainfall simulator. This means that there was some percolation and evaporation in the

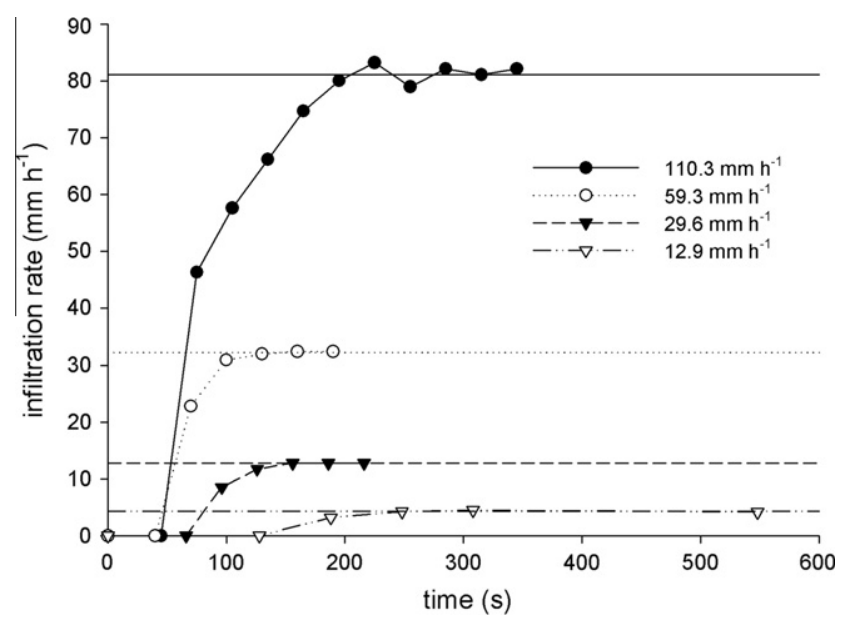

Fig. 2. Time progress of runoff rates for plot 11 . The legend gives the input rainfall intensities and the horizontal lines give the approximated steady state runoff rate levels. 
mean time, so that the first (and highest) rainfall intensity needed to rewet the soil a bit, which made the experiment typically last longer than the following (Fig. 2). Fig. 2 shows the progress of runoff rates, approaching steady state for plot 11 . On some other plots, the curves showed irregular oscillations, which may be due to the escape of entrapped air, for example from macropores, and subsequent filling with infiltration water. In general, infiltration rates are decreased by entrapped air (Wang et al., 1998). With the presented method it was not possible to estimate the error caused by air entrapment. When values did not change for three subsequent readings with more than ca. $5 \%$, which is the minimum accuracy of reading, steady state was assumed and a photo was taken. The average of the last three values was taken as an approximation for the steady state final runoff rate.

\subsection{Measurement of variables}

Large earthworm macropores ( $>4 \mathrm{~mm}$ diameter) were counted after plot installation and normalized to the number of one square meter, which yielded the macropore density (MAC, number $/ \mathrm{m}^{-2}$ ). Before the experiment, a photo was taken with the camera centred above the plot. Percentage residue cover (RC) and plant cover (PC) were derived from the photo by evaluating the presence of residue or plants at ca. 196 grid points. PC was geometrically corrected for bias caused by the plant height with: PC = uncorrected PC ((height of lens above soil surface - average plant height)/height of lens above soil surface $)^{2}$. Soil bulk density $\left(\rho_{\mathrm{b}}, \mathrm{g} \mathrm{cm}^{-3}\right)$ was determined with a Kopecki cylinder $\left(100 \mathrm{~cm}^{3}\right)$ in the surface layer $(0-5 \mathrm{~cm})$, percentage soil organic carbon (SOC) with the Walkley-Black method and texture with a Laser Diffraction Particle Size Analyzer (Beckman Coulter, LS 13 320).

Before the experiment, two roughness profiles were taken perpendicular to the sowing line that ran parallel with the slope. This was done with a pinmeter whose white pins were marked black at the top ends. Digital photos were taken from a $3 \mathrm{~m}$ horizontal distance to the pinmeter surface. Software aided colour recognition and a spline-interpolation created profiles with 120 height values with equal distances of $7.2 \mathrm{~mm}$. The profiles were corrected for slope trends, but a correction for oriented roughness was not necessary, because a clear tillage induced pattern was not present. Random roughness (RR) (Allmaras et al., 1966) and tortuosity (T) (Boiffin, 1984) indices were derived from the profiles. Also, an experimental variogram of each profile was modelled with a constant for the sill and a linear model for the ascending limb. The intersection of both lines defined the range.

Inundated area $\left(A_{i}\right)$ was defined as the surface area fraction where single grains and micro-aggregates were clearly inundated by either flowing or ponding water. Automated colour recognition of the ponded area on the digital photos was not possible, so we needed to determine $A_{i}$ by visual interpretation. Three digital transects were drawn perpendicular to the flow direction, one at the centre of the plot and the other two around one third from the upper and lower border. Transects on one plot, but at different rainfall intensities were drawn at exactly the same location. A digital ruler tool was used to measure the number of pixels showing inundation along the transects. $A_{i}$ was calculated by averaging the inundation fractions derived from each transect.

\subsection{Statistical analysis}

As tillage strips could not be arranged in a randomized block design for practical reasons, it had to be assumed that random soil variation between two plots within one tillage treatment is similar to the variation between two plots of two different tillage treatments. This assumption seems reasonable, because the distance between randomly chosen plots on the same tillage treatment was similar to the distance between plots on different tillage treatments.

The effects of tillage treatments and plot characteristics on infiltration were examined with a mixed model analysis using the mixed procedure of the SAS software (SAS Enterprise Guide 4.1). Linear mixed models were developed for two dependent variables: natural logarithm of $f(\ln f)$ and $A_{i}$. The variables used to build the statistical model consisted of both a class variable (tillage) and covariates (rainfall intensity and all other continuous variables mentioned in Table 1). Infiltration rates and inundation measured during the four rainfall intensities applied on one plot were repeated measures on the same plot and were therefore correlated. The mixed procedure is able to account for this. In order to identify the optimal variable subset that can significantly explain variation in the dependent variables, we used the log likelihood ratio test (Littell et al., 1996) and backward elimination of insignificant variables, using a significance level of $5 \%$.

\section{Results}

\subsection{Soil and surface properties}

The reduced tillage treatment (RT) had higher mean values of macropore density (MAC), percentage residue cover (RC), random roughness (RR), tortuosity $(T)$, sill, range, soil organic carbon (SOC) and percentage sand, but lower plant cover (PC) and percentage clay than conventional tillage (CT). Bulk density $\left(\rho_{\mathrm{b}}\right)$ was the same in both treatments. Standard deviations were generally higher for RT than for CT, with the exception of bulk density, sand, clay and soil organic carbon.

\subsection{Infiltration and inundation data}

Steady state final infiltration rate $(f)$ is plotted against rainfall intensity $(r)$ in Fig. 3. The variation of absolute infiltration values increased with $r$. The White and Breusch-Pagan tests on heteroscedasticity suggested that variation increased exponentially. A conversion of $f$ and $r$ to its natural logarithms created $\ln (f)$ values that were evenly distributed over the $\ln (r)$ scale, with constant variations. After transformation the dataset did not show any significant heteroscedasticity anymore. The exponential model (Eq. (1)) was fitted to this converted data, because a model fitted to unconverted data would violate the assumption of normality and be biased by heteroscedasticity. However, in both cases the

Table 1

Soil (0-5 cm depth) and surface properties of CT and RT plots $(n=18)^{\mathrm{a}}$.

\begin{tabular}{|c|c|c|c|c|c|c|c|c|c|c|c|c|}
\hline Tillage & & MAC $\left(\mathrm{nm}^{-2}\right)$ & PC (\%) & $\mathrm{RC}(\%)$ & $\mathrm{RR}(\mathrm{mm})$ & $T(-)$ & Sill $\left(\mathrm{mm}^{2}\right)$ & Range (mm) & $\rho_{\mathrm{b}}\left(\mathrm{g} \mathrm{cm}^{-3}\right)$ & SOC (\%) & Sand (\%) & Clay (\%) \\
\hline \multirow[t]{2}{*}{ CT } & Mean & 54.2 & 43.9 & 4.3 & 5.2 & 1.07 & 37.5 & 92.2 & 1.36 & 0.63 & 31.7 & 7.0 \\
\hline & St. Dv. & 16.2 & 5.1 & 2.1 & 0.9 & 0.01 & 13.8 & 33.9 & 0.08 & 0.14 & 4.2 & 1.2 \\
\hline \multirow[t]{2}{*}{ RT } & Mean & 74.1 & 34.6 & 11.7 & 6.5 & 1.10 & 64.7 & 140.2 & 1.37 & 0.80 & 33.8 & 6.3 \\
\hline & St. Dv. & 31.7 & 6.1 & 3.6 & 1.3 & 0.02 & 36.1 & 58.5 & 0.04 & 0.05 & 2.8 & 1.1 \\
\hline
\end{tabular}

a MAC: macropore density, PC: plant cover, RC: residue cover, RR: random roughness, $T$ : tortuosity, $\rho_{\mathrm{b}}$ : bulk density, SOC: soil organic carbon. 


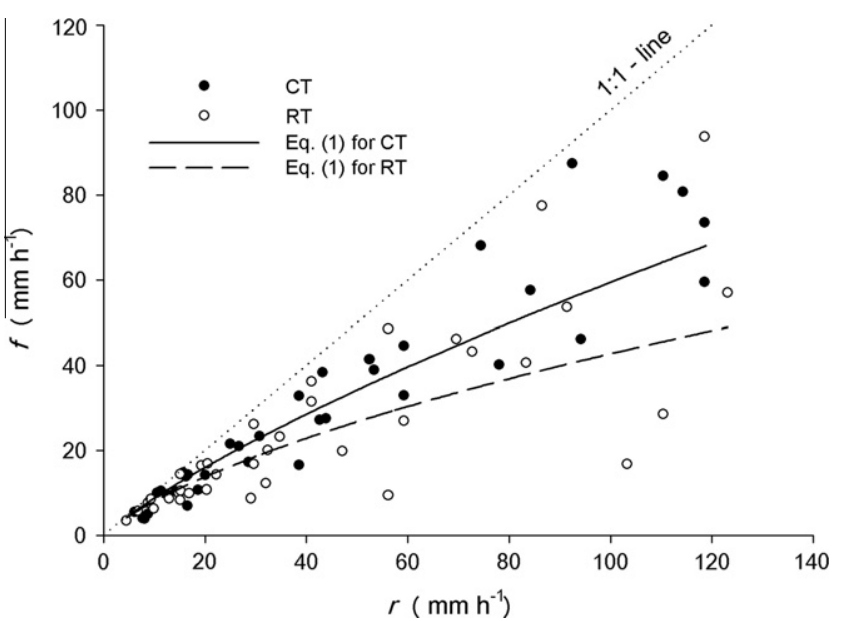

Fig. 3. Final, steady state infiltration $(f)$ vs. rainfall intensity $(r)$. Data from CT and RT plots are modelled separately with $\ln (f)$ and $\ln (r)$ values with Eq. (1).

parameter $f_{\max }$ is biased, and it appears to be problematic to apply the model or Hawkins and Cundy (1987) correctly in this study. Hence, fitting Eq. (1) to the logarithmic data gives a suitable description of the data in terms of fit, without allowing for any physical interpretation. The best fit was obtained with the FIT statement in the MODEL procedure of SAS, separately for CT and RT (CT: $n=36, R^{2}=0.91$; RT: $n=36, R^{2}=0.75$ ) (Fig. 3 ). The fit was better for CT than for RT, reflecting the higher variability of RT.

The inundated area fraction is given in Fig. 4. $A_{i}$ increased stronger at lower $r$ than at higher $r$. The variation of the $A_{i}$ values was relatively constant throughout the range of $r$.

\subsection{Statistical analysis}

Eq. (2) gives the mixed model for the prediction of the natural logarithm of the final infiltration rate $\ln (f)$ and Table 2 entails information about the significance of effects and model performance.

$$
\begin{aligned}
\ln (f)= & 0.822 \ln (r) \mathrm{RT}+0.9741 \ln (r) \mathrm{CT}+0.04725 \mathrm{RC} \\
& -0.3536 \rho_{b}
\end{aligned}
$$

Ln-transformed values of both $r$ and $f$ were chosen, because of the earlier mentioned heteroscedasticity and approximate

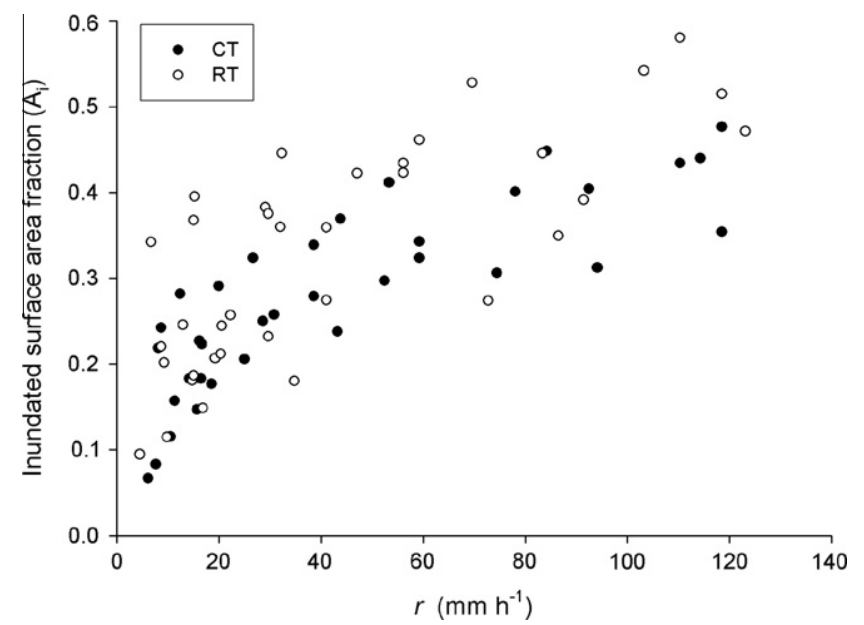

Fig. 4. Observed inundated surface area fraction $\left(A_{i}\right)$ vs. rainfall intensity $(r)$ classified by tillage.
Table 2

Model description for Eq. (2) ( $n=72)$ and Eq. (3) ( $n=71)$; RC: residue cover $\rho_{\mathrm{b}}$ : bulk density.

\begin{tabular}{lll}
\hline & $\ln (f)($ Eq. $(2))$ & $\mathrm{A}_{\mathrm{i}}$ (Eq. $\left.(3)\right)$ \\
\hline RT (reduced tillage); & True $=1 ;$ false $=0$ & True $=1 ;$ false $=0$ \\
CT (conventional tillage) & & \\
Type III $F$ statistic & $\ln (r): p<0.0001$ & \\
& $\ln (r) *$ tillage: $p<0.0001$ & $r: p<0.0001$ \\
& RC: $p<0.001$ & Tillage: $p<0.01$ \\
& $\rho_{\mathrm{b}}: p<0.01$ & \\
Model efficiency (ME) & 0.87 & 0.62 \\
Mean absolute error & 0.72 & 0.10 \\
\hline
\end{tabular}

$\log -\log$ linearity. Tillage treatment was tested first. It had a significantly different slope with $r$, which means that the effect of rainfall intensity was dependent on tillage. RT and CT are dummy variables that determine which parameter for rainfall intensity is used (Table 2). An intercept was excluded as insignificant. Once this basic model structure had been established, it was checked whether additional variables could significantly improve the model. Residue cover (RC) and bulk density $\left(\rho_{\mathrm{b}}\right)$ were the variables that best improved the model, regarding the log likelihood. The effect of these variables seemed to be independent of the tillage treatment, and parameters could be applied for both treatments. Other variables and variable combinations rather deteriorated the $\log$ likelihood. The Nash and Sutcliffe model efficiency was good, with $\mathrm{ME}=0.87$. Eq. (3) gives the mixed model for the inundated area fraction at steady state $\left(A_{i}\right)$ and Table 2 gives additional information on the model.

$A_{i}=0.217 \mathrm{RT}+0.16373 \mathrm{CT}+0.002604 r$

As there was no heteroscedasticity in the data, no transformation of $r$ was necessary. Again, tillage was checked first. For $A_{i}$, the effect of rainfall intensity was not significantly different for the two tillage treatments, so that a common slope model was used. No other variables could significantly improve the model, regarding the log likelihood. Model efficiency was fairly good, with $\mathrm{ME}=0.62$.

Fig. 5a and $\mathrm{b}$ shows the observed versus predicted values for the two models. Fig. 5a shows that the prediction of $\ln (f)$ had no systematic deviations from the 1:1 line. A linear mixed model seemed to be appropriate in this case. Fig. 5b shows that low values of $A_{i}$ were clearly over-estimated. The choice of a linear mixed model for the prediction of $A_{i}$ has the background that at the present stage of research not enough data has been gathered and analysed that would allow the establishment of a non-linear or segmented model.

The results of the statistical analysis indicate that rainfall intensity had a highly significant effect on the dependent variables. The interaction term $r *$ tillage was significant in the infiltration model (Eq. (2)). At higher rainfall intensities, the difference between the tillage treatments became more pronounced, values for RT being lower than for CT. Tillage alone had no significant effect on $f . A_{i}$ did not show an interaction between rainfall intensity and tillage, rather, tillage treatments had different intercepts but the same slopes.

\subsection{Qualitative analysis}

The statistical analysis did not allow us to identify much of the variation of the infiltration model, nor did it reveal the underlying mechanisms explaining the nature and strength of the $A_{i}-r$ relationship. By studying the inundation photos in more detail, typical 
(A)

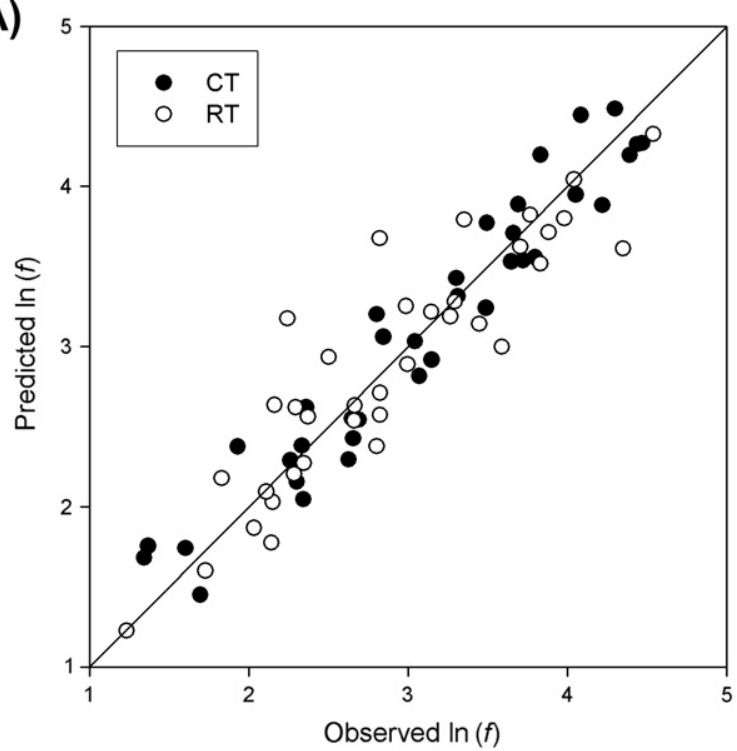

(B)

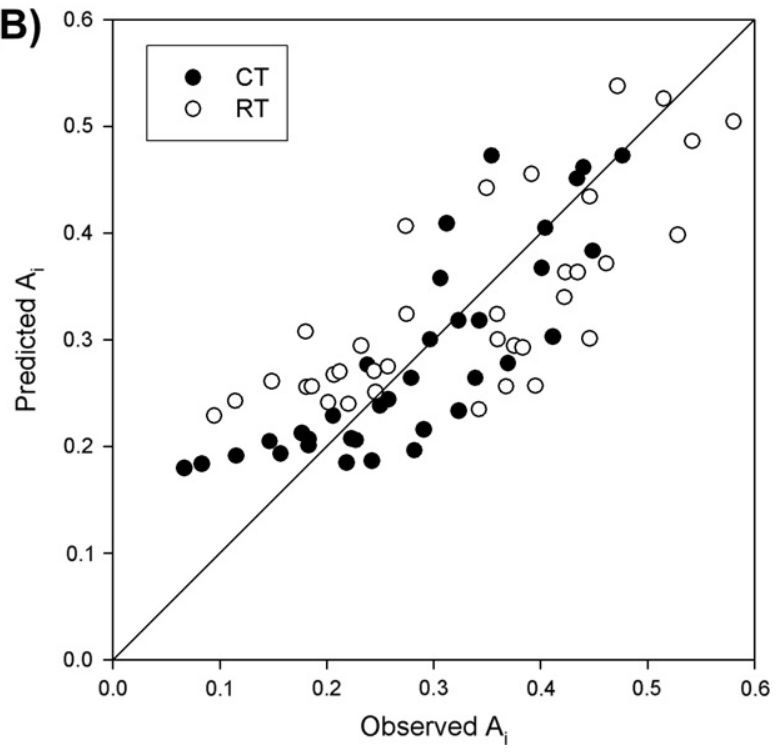

Fig. 5. Observed vs. predicted data points for the two dependent variables, classified by tillage: (a) $\ln (f)$ (Eq. (2)) and (b) $A_{i}$ (Eq. (3)).

cases could be found that have some potential for extending the explanation beyond the statistical analysis.

The relationship between the infiltration coefficient (IC), defined as IC $=f / r$, and $r$ was qualitatively analysed by comparing the four values of each plot with the appropriate inundation photos. RT-plots 3 and 5 (Fig. 7) were selected as typical cases to be discussed and are displayed as graphs in Fig. 6. While the infiltration coefficient remained more or less constant on plot 3 , plot 5 showed a decline of the infiltration coefficient with rainfall intensity. A quantification of the area fraction of the sedimentary seal $\left(A_{\text {sed }}\right)$ that covers the main channel and micro-depression network was difficult; however, it was delineated for the two shown plots (transparent white area in Fig. 7). Plot 3 had a low $A_{\text {sed }}$ that was well connected to the outlet (white arrows in Fig. 7a) and a low random roughness of $4.1 \mathrm{~mm}$. Plot 5 had a deep central microdepression that was covered by an extended sedimentary seal and a high random roughness of $8.2 \mathrm{~mm}$. White arrows in Fig. 7b show the spill-points of the depression at higher rainfall intensities.

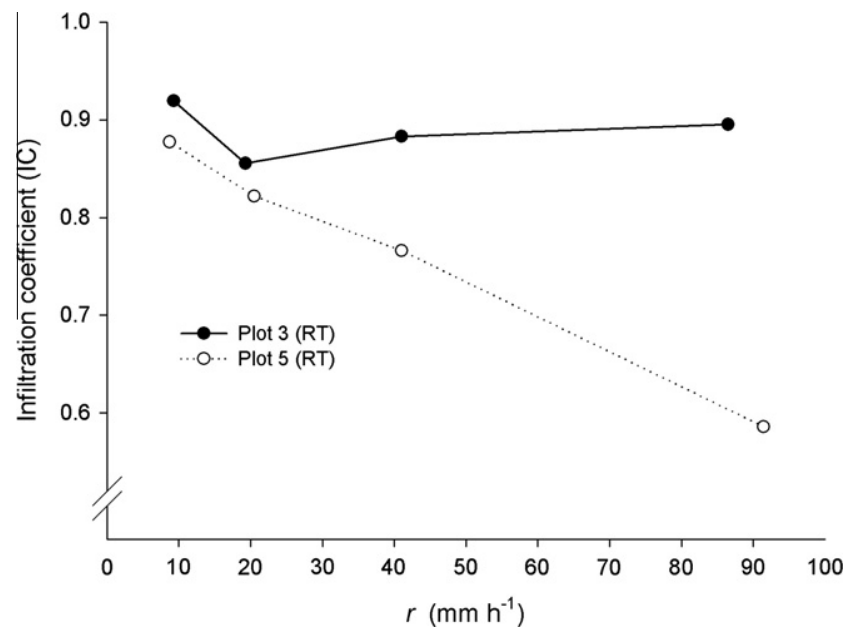

Fig. 6. Observed infiltration coefficient vs. rainfall intensity for two contrasting plots (3 and 5) under RT.

\section{Discussion}

\subsection{A dynamic $K_{e}$}

The results show that it is possible to model $K_{\mathrm{e}}$ as a function of mainly rainfall intensity, which has been demonstrated with a limited dataset derived from one agricultural field. The experimental setup with the drop infiltrometer is well suited to derive the necessary relationships, as drop impact is limited, a wide range of intensities can be easily set and adjusted and the measurement scale of 0.8 by $0.8 \mathrm{~m}^{2}$ is meaningful, because it comprises relevant micro-topographical heterogeneities. Measuring different intensities on one plot is fast compared to installing a new plot per rainfall intensity. Steady state was usually reached after 3-10 min (Fig. 2).

This study shows that predictions of $K_{\mathrm{e}}$ correspond well to field observations, when rainfall intensity is used as a dynamic input variable. The application in infiltration models should not pose any theoretical problem, keeping in mind that rainfall intensity is a statistical proxy for effects of heterogeneity on hydraulic conductivity. Rainfall intensity-dependency of $K_{\mathrm{e}}$ is closely related to runoff, which can also increase inundation of the microtopography and thereby the effective hydraulic conductivity. Accumulation of runoff may lead to generally increasing infiltration in the downslope direction, leading to a decrease of runoff per unit area and a degressive increase of total runoff under steady state conditions. This scale dependency of runoff and erosion has been reported by many authors (Cerdan et al., 2004; Lal, 1997; Parsons et al., 2006; van de Giesen et al., 2000). Modelling $K_{\mathrm{e}}$ in dependence of rainfall intensity could be a step towards improved hillslope infiltration excess runoff and erosion models.

\subsection{Tillage and infiltration}

Usually, reduced tillage plots produce less runoff than conventional tillage plots (Leys et al., 2007; Tebrugge and During, 1999). Furthermore, Lal (1997) found that scale effects are much stronger on reduced than on conventional tillage. Common explanations for the infiltration increasing effect of reduced tillage are: the effect of residue cover to decelerate runoff and prevent surface sealing (Mannering and Meyer, 1963; Ruan et al., 2001; Trojan and Linden, 1998), abundance of earthworm burrows that increase preferential flow (Valckx, unpublished results; Ehlers, 1975; Weiler and Naef, 2003) and a higher level of surface soil organic matter that increases aggregate stability and prevent structural sealing and 
(A) Plot 3

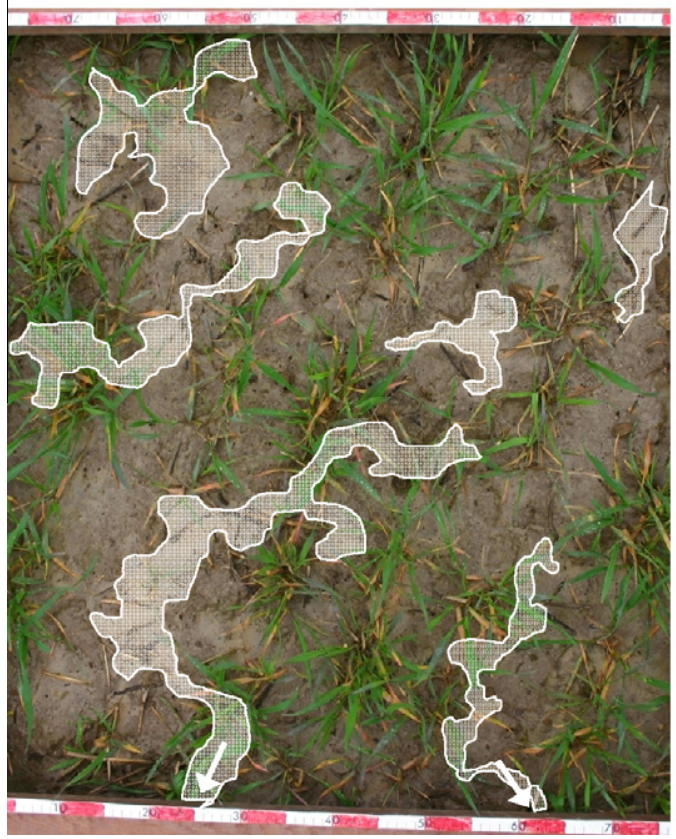

(B) Plot 5

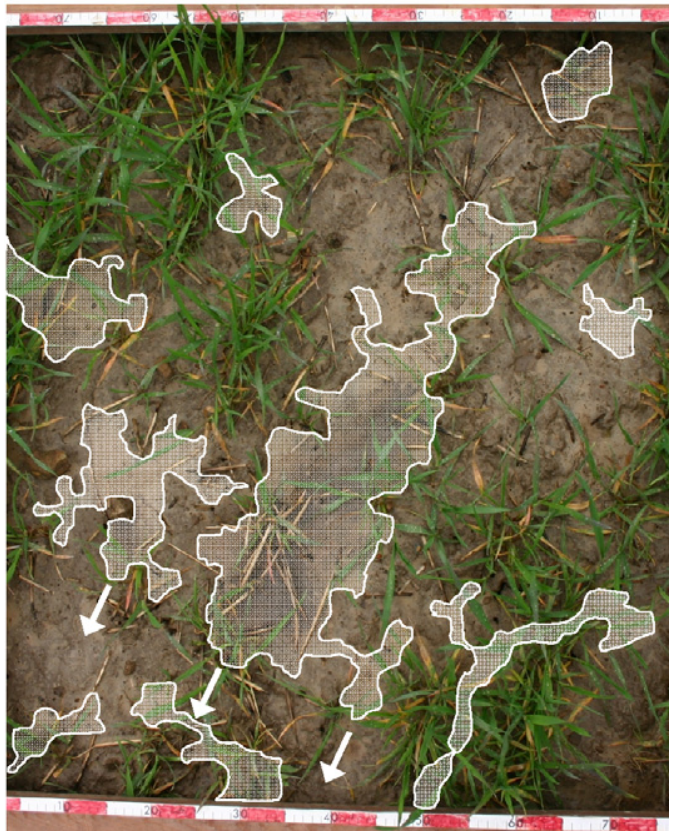

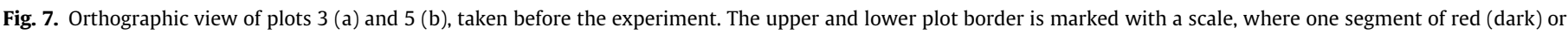

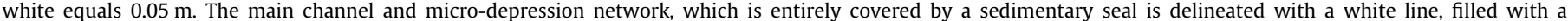
transparent white shade. The white arrows in (a) mark the outflow from the plot, while in (b) they mark the points where water spills from the central depression.

retain surface random roughness throughout the growing season (Govers et al., 2000; Tebrugge and During, 1999). These observations are generally confirmed by our measurements (Table 1), except that RT has actually a lower infiltration rate at steady state than CT. As data of only one field and one season are the basis of the presented results, specific conditions of the field may be the cause for this.

The statistical analysis shows that the effect of tillage on infiltration cannot be seen detached from rainfall intensity (Eq. (2)), because the way tillage influences infiltration is dependent on rainfall intensity. For example, preferential flow increases with inundation, as gradually earthworm burrows become inundated with increasing rainfall intensity (Weiler, 2005), which was actually observed on some plots in this study. The importance of residue cover and bulk density for infiltration is supported by the statistical analysis (Eq. (2)). But the study also shows that it remains difficult to explain the variability of infiltration, because many of the measured variables that are believed to be significantly related to infiltration could not be used in the model. Also, the exact composition of factors and coefficients can of course change when more fields, and thus more variability, are introduced as empirical basis for the model.

\subsection{Inundation and sedimentary sealing}

Inundated area fraction was significantly higher on RT than CT (Eq. (3), Fig. 4), but there was only a rainfall intensity effect and no interaction effect between tillage and rainfall intensity, in contrast to Eq. (2). This means that $A_{i}$ is constantly higher on RT than on CT over the whole range of rainfall intensities. It seems reasonable to state that this constant difference is caused not so much by a dynamic rainfall-intensity related factor, but by some structural properties of the surface, such as the extent of a sedimentary seal, where ponding easily occurs. Inundation-effects that increase infiltration would be expected at high rainfall intensities and with $A_{i}$ extending beyond the extent of the sedimentary seal.
Unfortunately, as long as we do not have a suitable methodology to measure the extent of the sedimentary seal, this hypothesis remains unsupported by data.

The results of the qualitative analysis could be interpreted in the following way. Relatively stable aggregates, mixed with residues at the surface, dominate the reduced tillage treatment and easily trap detached fine sand that can form a sedimentary seal. The form of the IC-graph (Fig. 6) then might depend on the actual depth and connectivity of micro-depressions. Plot 3 had a relatively low random roughness with well connected channels that could more easily evacuate the fine sand. At higher rainfall intensities there was much direct infiltration and infiltration through inundated or less sealed area, leading to a high IC. Plot 5, in contrast, had a relatively high random roughness, badly connected with the plot outlet. An extended sedimentary seal could develop. The infiltration coefficient drops with increasing rainfall intensity, as more and more of the micro-depressions start contributing to runoff. From the qualitative analysis it follows that infiltration rate is not related to ponding depth in a simple way, but microtopography and sealing conditions determine a more complicated interaction. To disentangle this, indicators would need to be found to not only model ponding and runoff connectivity within the microtopography (Antoine et al., 2009), but to relate this to infiltration.

\subsection{The challenge of modelling $K_{e}$ for field-scale infiltration}

Future research with the aim of improving our concepts of infiltration capacity and the performance of runoff and erosion models could focus on the interaction of sedimentary seal, preferential flow, inundation and rainfall intensity. When more than one field and a wider range of slopes and soil types become basis and scope for predictions, the models in this study need to be extended or adapted. But also then, $K_{\mathrm{e}}$ values derived from the models should not be used as average for the whole field, because possible effects of runoff concentration, run-on and the associated inundation of the microtopography on infiltration capacity can alter these 
capacities and cause scale effects (Leys et al., unpublished results). Modelling runoff at hillslope scale also requires knowledge of connectivity patterns and scale-dependent processes (Bracken and Croke, 2007; Sidle, 2006). Transmission processes require an event-based distributed modelling approach, where inundation and rainfall intensity dynamically determine the local effective $K_{\mathrm{e}}$. For modelling infiltration throughout the vegetation period after tillage, $K_{\mathrm{e}}$ values should also be considered transient. Their evolution can be related to rainfall kinetic energy and biological activity that require parameter calibration during time after tillage (Brakensiek and Rawls, 1983; Risse et al., 1995).

\section{Conclusion}

For the purpose of studying the relationship between rainfall intensity and infiltration a drop infiltrometer was developed that is able to produce a wide range of simulated rainfall intensities on a meaningful scale. Furthermore, photos of the soil surface were taken during the infiltration experiments for the determination of the inundated surface fraction $\left(A_{i}\right)$. The combination of drop infiltrometer results with surface photos allowed us to establish functional relationships between rainfall intensity, infiltration and inundation. The results show that a variable intensity drop infiltrometer can be used to quantify the rainfall-infiltration relationship at varying intensities.

The data show that there is no constant final infiltration capacity on sealed agricultural soils that represents the averaged effective hydraulic conductivity. In a highly heterogeneous soil structure with macroporosity, sealing patterns and plants $K_{\mathrm{e}}$ depends on the degree of inundation and direct rainfall input. A practical approach to account for this is to model a dynamic $K_{\mathrm{e}}$ in a statistical way. In our study we did this with a mixed linear model that relates $\ln (f)$ to $\ln (r)$ (Eq. (2)). The effect of rainfall intensity on infiltration was different for tillage treatments. Statistical analysis and observations indicate that percentage residue cover, bulk density, area fraction covered by a sedimentary seal and macroporosity determine the variation of $K_{\mathrm{e}}$. There are strong indications that inundation is mainly determined by sedimentary sealing and microtopography, but its interaction with infiltration and rainfall intensity remains an issue for future research.

This study shows that the assumption of homogenous soil and surface conditions or the application of an averaged, constant $K_{\mathrm{e}}$ is problematic. It gives empirical evidence that $K_{\mathrm{e}}$ is dependent on $r$ and explores the role of tillage and inundation of the microtopography. It can be generally expected that an effective hydraulic conductivity, which is defined within a framework of dynamic hydrological and hydraulic variables will increase the performance of distributed models. Consequently, this approach might contribute to meeting problems of heterogeneity and scale within an agricultural hillslope.

\section{Acknowledgements}

We would like to thank all who helped with the data collection and fieldwork preparation, especially Mustapha Ayyad, Greet Dielis and Jos Meersmans. The project was sponsored by the Flemish Agency for Innovation by Science and Technology (IWT).

\section{References}

Allmaras, R.R., Burwell, R.E., Larson, W.E., Holt, R.F., 1966. Total porosity and random roughness of the interrow zone as influenced by tillage. USDA Conserv. Res. Rep., vol. 6, pp. 1-22.

Antoine, M., Javaux, M., Bielders, C., 2009. What indicators can capture runoffrelevant connectivity properties of the micro-topography at the plot scale? Advances in Water Resources 32 (8), 1297-1310.
Boiffin, J., 1984. La dégradation structurale des couches superficielles du sol sous l'action des pluies. Thèse de doctorat d'ingénieur Thesis. Université de soutenance, Paris-Grignon.

Bracken, L.J., Croke, J., 2007. The concept of hydrological connectivity and its contribution to understanding runoff-dominated geomorphic systems. Hydrological Processes 21 (13), 1749-1763.

Brakensiek, D.L., Rawls, W.J., 1983. Agricultural management effects on soil-water processes. 2. Green and Ampt parameters for crusting soils. Transactions of the ASAE 26 (6), 1753-1757.

Bresson, L.M., Boiffin, J., 1990. Morphological characterization of soil crust development stages on an experimental field. Geoderma 47 (3-4), 301-325.

Cerdan, O. et al., 2004. Scale effect on runoff from experimental plots to catchments in agricultural areas in Normandy. Journal of Hydrology 299 (1-2), 4-14.

Darboux, F., Gascuel-Odoux, C., Davy, P., 2002. Effects of surface water storage by soil roughness on overland-flow generation. Earth Surface Processes and Landforms 27 (3), 223-233.

Dunne, T., Zhang, W.H., Aubry, B.F., 1991. Effects of rainfall, vegetation, and microtopography on infiltration and runoff. Water Resources Research 27 (9) 2271-2285.

Ehlers, W., 1975. Observations on earthworm channels and infiltration on tilled and untilled loess soil. Soil Science 119 (3), 242-249.

Fox, D.M., Le Bissonnais, Y., Bruand, A., 1998. The effect of ponding depth on infiltration in a crusted surface depression. Catena 32 (2), 87-100.

Govers, G., Takken, I., Helming, K., 2000. Soil roughness and overland flow. Agronomie 20 (2), 131-146.

Hawkins, R.H., Cundy, T.W., 1987. Steady-state analysis of infiltration and overlandFlow for spatially-varied hillslopes. Water Resources Bulletin 23 (2), 251-256.

Jetten, V., de Roo, A., Guerif, J., 1998. Sensitivity of the model LISEM to variables related to agriculture. Modelling Soil Erosion by Water 55, 339-349 (531).

Karssenberg, D., 2006. Upscaling of saturated conductivity for Hortonian runoff modelling. Advances in Water Resources 29 (5), 735-759.

Lal, R., 1997. Soil degradative effects of slope length and tillage methods on alfisols in western Nigeria. 1. Runoff, erosion and crop response. Land Degradation \& Development 8 (3), 201-219.

Leonard, J., Ancelin, O., Ludwig, B., Richard, G., 2006. Analysis of the dynamics of soil infiltrability of agricultural soils from continuous rainfall-runoff measurements on small plots. Journal of Hydrology 326 (1-4), 122-134.

Leys, A., Govers, G., Gillijns, K., Poesen, J., 2007. Conservation tillage on loamy soils: explaining the variability in interrill runoff and erosion reduction. European Journal of Soil Science 58 (6), 1425-1436.

Littell, R.C., Milliken, G.A., Stroup, W.W., Wolfinger, R.D., 1996. SAS System for Mixed Models. SAS Institute Inc., Cary, NC. p. 663.

Mannering, J.V., Meyer, L.D., 1963. The effects of various rates of surface mulch on infiltration and erosion. Soil Science Society of America Journal 27 (1), 84-86.

Parsons, A.J., Brazier, R.E., Wainwright, J., Powell, D.M., 2006. Scale relationships in hillslope runoff and erosion. Earth Surface Processes and Landforms 31 (11) 1384-1393.

Reeves, M., Miller, E.E., 1975. Estimating infiltration for erratic rainfall. Water Resources Research 11 (1), 102-110.

Risse, L.M., Nearing, M.A., Zhang, X.C., 1995. Variability in Green-Ampt effective hydraulic conductivity under fallow conditions. Journal of Hydrology 169 (1-4), $1-24$.

Ruan, H.X., Ahuja, L.R., Green, T.R., Benjamin, J.G., 2001. Residue cover and surfacesealing effects on infiltration: numerical simulations for field applications. Soil Science Society of America Journal 65 (3), 853-861.

Sidle, R.C., 2006. Field observations and process understanding in hydrology: essential components in scaling. Hydrological Processes 20 (6), 1439-1445.

Stone, J.J., Paige, G.B., Hawkins, R.H., 2008. Rainfall intensity-dependent infiltration rates on rangeland rainfall simulator plots. Transactions of the ASABE 51 (1), 45-53.

Tebrugge, F., During, R.A., 1999. Reducing tillage intensity - a review of results from a long-term study in Germany. Soil \& Tillage Research 53 (1), 15-28.

Trojan, M.D., Linden, D.R., 1998. Macroporosity and hydraulic properties of earthworm-affected soils as influenced by tillage and residue management. Soil Science Society of America Journal 62 (6), 1687-1692.

van de Giesen, N.C., Stomph, T.J., de Ridder, N., 2000. Scale effects of Hortonian overland flow and rainfall-runoff dynamics in a West African catena landscape. Hydrological Processes 14 (1), 165-175.

Veihe, A., Quinton, J., 2000. Sensitivity analysis of EUROSEM using Monte Carlo simulation I: hydrological, soil and vegetation parameters. Hydrological Processes 14 (5), 915-926.

Verstraeten, G. et al., 2003. Integrating science, policy and farmers to reduce soil loss and sediment delivery in Flanders, Belgium. Environmental Science \& Policy 6 (1), 95-103.

Wang, Z., Feyen, J., van Genuchten, M.T., Nielsen, D.R., 1998. Air entrapment effects on infiltration rate and flow instability. Water Resources Research 34 (2), 213222.

Weiler, M., 2005. An infiltration model based on flow variability in macropores: development, sensitivity analysis and applications. Journal of Hydrology 310 (1-4), 294-315.

Weiler, M., Naef, F., 2003. Simulating surface and subsurface initiation of macropore flow. Journal of Hydrology 273 (1-4), 139-154.

Yu, B., Rose, C.W., Coughlan, K.J., Fentie, B., 1997. Plot-scale rainfall-runoff characteristics and modeling at six sites in Australia and Southeast Asia. Transactions of the ASAE 40 (5), 1295-1303. 